\title{
O QUE PODE UMA ANTROPOLOGIA AUDIOVISUAL?
}

Hércules Gomes de Lima

Universidade Federal do Ceará

Universidade da Integração Internacional da Lusofonia Afro-Brasileira

Programa de Pós-Graduação em Antropologia Social | Fortaleza, Brasil limaa.hercules@gmail.com | ORCID iD: 0000-0001-6475-9575

PIAULT, Marc Henri. 2018. Antropologia e cinema: passagem à imagem, passagem pela imagem. São Paulo: Editora Unifesp. 432p.

$\mathrm{C}$ hega, enfim, a tradução de uma obra fundamental, não somente para o campo da antropologia visual, como também para a disciplina antropológica em geral. Ecoo as palavras de Cornelia Eckert, no Prefácio, sobre este livro que, originalmente publicado em 2000, Marc H. Piault acompanha e explora as interseções, os cortes, as similitudes e as diferenças nos percursos trilhados pela antropologia e pelo cinema na história do pensamento ocidental. Ao habitar essa fronteira, o cineastaantropólogo promove uma torção nos modos de compreender e praticar ambas as disciplinas ao atentar, como ponto de partida, aos seus contextos de surgimento, quais sejam: os regimes de expansão, dominação e exploração colonial de territórios e de povos além-mar em nome da "civilização" e da "evolução" (:14).

O livro se divide em 11 capítulos, além de uma curta Introdução. Nesta, o autor afirma que a produção audiovisual acabou por ocupar uma posição subalterna na disciplina antropológica, motivada por certo positivismo e cientificismo em sua gênese, elegendo os textos como meios válidos de conhecimento em detrimento de outros. Em sua posição 
rebaixada, as imagens seriam lidas enquanto meras ilustrações que conferem e atestam a cientificidade dos dados coletados. Contra esta marca da produção e uso de imagens dentro da disciplina, Piault assinala que a "passagem à imagem", para levar a sério a possibilidade de uma antropologia visual - "ou melhor, audiovisual" (:20) - torna a reflexão mais complexa ao envolver, entre outros, o próprio ato de captura e os limites do encontro etnográfico. Nesse sentido, a antropologia audiovisual anteciparia algo que ressurgiria, de modo radical nas décadas 1970-1980, com as críticas do dito movimento pós-moderno, representado exemplarmente por Writing Culture(CLIFFORD \& MARCUS 1986) à relação de poder entre o pesquisador e seus interlocutores e informantes.

Os dois primeiros capítulos (Nascimento do Cinematógrafo, Nascimento da Antropologia e Que fazer dos últimos selvagens.?) traçam as homologias entre o cinema e a antropologia em relação aos seus objetivos iniciais: explorar a possibilidade, para o público europeu, de acessar mundos distantes, um "Outro" exótico e desconhecido. A invenção dos primeiros aparelhos de gravação foi seguida de seu uso para documentar práticas de povos indígenas na América (William Dickson, em 1894, entre os Sioux) e na África (Félix-Louis Regnault, durante exposição em Paris em 1895, filma "uma 'mulher ouolove' modelando cerâmica"). O "cinema do real" e a "etnologia do resgate" do fim do século XIX e início do século XX permitiriam um meio seguro para manter viva a imagem destas sociedades distantes, garantindo o registro como descobertas, antes de seu desaparecimento, tal como previa o modelo evolucionista em voga. $\mathrm{O}$ estilo dos filmes, curtos e sem som direto, era marcado pela câmera parada captando ações como preparo de fogo e danças rituais. A estranheza frente aos equipamentos e possíveis constrangimentos que causavam aos "nativos" já eram perceptíveis, contudo, longe de encerrar sua capacidade de captar a realidade, como instrumento da objetivação do olhar $(: 41)$.

No terceiro capítulo (Rumo a uma nova linguagem), Piault argumenta que o estatuto de tradução objetiva do real pelo cinema é posto em xeque. Antes que limitado à uma instrumentalização, o cinema e seus equipamentos exigiriam uma atenção específica pois criariam uma linguagem com aspectos próprios a fim de narrar os acontecimentos, jogar com a objetividade e a subjetividade (:60). O filme é um recorte no espaço e no tempo, potente em si mesmo, que dá a ver 
interpretações diversas a partir do "choque das imagens", somando, recortando e montando planos, cores, luzes, formas, paisagens... Assim, antes que ser um acesso privilegiado ao Real, o cinema reconhece a questão das intencionalidades e das posições e, inclusive, a possibilidade de constituir um diálogo "entre o diretor, aqueles cujas as imagens são captadas por ele e aqueles para quem ele as projeta" (:60-61). Nesse ínterim, as teorias da montagem ganham corpo a fim de explorar os termos e as relações particulares da linguagem cinematográfica, explicitam o rompimento com a narratividade linear da literatura e da dramaturgia - evidente, por exemplo, em $U m$ Homem com uma câmera (1929) de Dziga Vertov - para fornecer um "saber por imagens" e a capacidade da aliança entre antropologia e documentários para "produzir conceitos" (: 65).

As questões inauguradas pela admissão (ou, ao menos, problematização) da linguagem cinematográfica, na prática documental na relação com o trabalho etnológico, permanecem no centro do debate até os dias atuais - como atesta o autor no quarto capítulo (Problemas de Ontem, Problemas de Hoje) - e podem ser sumarizadas em: 1) as relações entre diretores cineastas e antropólogos: o discurso científico que tomava somente a instrumentalidade dos equipamentos dá lugar à admissão de uma intencionalidade necessária nos modos de captação da realidade, um recorte do olhar particular se faz presente; 2) a relação entre realidade e ficção: a captura e a intenção de conservação de culturas outras explora, desde o início, o uso de artifícios, intervenções e reconstituições para melhor explorar o "real". As "etnoficções" de Edward S. Curtis, em 1912, entre os ameríndios já exploravam a "ideia de uma organização ficcional da realidade" (:72); 3) as "condições e limites da reconstituição": seria levar a sério o espaço intersticial entre ficção, realidade e reconstituição e explorar, enquanto linguagem, as possibilidades explicativas do filme, que modos específicos de "dar a ver" o mundo podem ser gerados; e, por último, 4) a permanência em campo, o retorno e a avaliação dos materiais produzidos pelos até então "objetos" filmados. O contexto, a relação etnográfica, é fundamental para uma captura particular da intimidade entre os participantes do filme, inclusive com seus realizadores. Assim, explorando tais questões, o "paradigma da pintura" é quebrado, a câmera agora acompanha o movimento, participa no tempo e espaço junto àqueles em sua mira (:85).

Ainda no capítulo seguinte (Os Pais Fundadores), Piault busca demonstrar como tais questões fundamentais aparecem 
pelo/no legado de dois nomes marcantes para o surgimento de uma antropologia visual e de seu objetivo legítimo, a saber: a "transcrição em e pela imagem e som da construção do ser humano em sociedade" (:91). Aos moldes de uma "descrição compreensiva", o reconhecimento de uma multiplicidade de pontos de vista repensaria o lugar da descrição, do antropólogo, do equipamento fílmico... Antes que retornar a um relativismo genérico, o autor informa que não se trata de perder no horizonte as posições de poder, os lugares e contextos de violências, as hierarquias e os discursos. Aqui, ele se aproxima daquilo chamado por Roy Wagner (2018), em A Invenção da Cultura, de "objetividade relativa", a torção metodológica e epistemológica no ato de relacionar culturas diferentes, levando em conta a diversidade de discursos e possibilidades tradutivas.

Os "pais fundadores" têm contribuições distintas ao campo: primeiro, Dziga Vertov, cineasta russo, já comentado pela reflexão e abertura a uma busca em torno da linguagem cinematográfica por meio da montagem. Esta, a montagem, seria a grande matriz de sentidos, o rearranjo organizado do visível que alinharia os diferentes olhares no real a partir de técnicas diversas e se fazendo compreensível aos espectadores. $\mathrm{O}$ sentido estaria no próprio desvelamento e interação das imagens, sem o auxílio pedagógico do som e palavras, e se faria evidente por meio da exposição de seus intervalos, acompanhando o movimento maquínico de seu material e da "vida de improviso" e, enfim, explorá-lo a fim de construir um saber pelas e nas imagens. O segundo seria Robert Flaherty que junto, por um longo período de tempo, à vida de uma "família esquimó" (Inuit), realizou o filme Nanook, o Esquimó (1922), expondo o cotidiano, a intimidade da relação dos indivíduos com as condições de seu ambiente, alguns hábitos e práticas, como a caça a focas. Apesar de certas intenções antropológicas (o sabor artesanal à vida e aos assuntos cotidianos), a apresentação imagética que faz Flaherty de seus interlocutores é a representação idealizada do Ocidente sobre povos que lutam contra uma Natureza dura e fria, difícil e laboriosa, reafirmando um tom de selvageria predominante e subalternidade intelectual e social. Combinando as contribuições de ambos os cineastas, poderíamos vislumbrar o presságio das "antropologias partilhadas", dialógicas: a montagem, o rearranjo do real e a atenção e a criação de intimidade, relação entre as partes que realizam o filme, enfim, o cinema como espaço de interlocução e mediação. 
$\mathrm{Na}$ continuação dos nomes importantes para a concretização da área de antropologia visual, aqueles que abrem as portas da "etnologia com imagem", estão Marcel Griaule e Franz Boas (entusiastas do uso de imagens e sons para registro como ferramenta de grande valor heurístico) e Margaret Mead e Gregory Bateson (além do instrumental, havia a possibilidade de comparação e experimentação, captação das ideias, valores, comportamentos das culturas, seu "discurso interior"). O sexto capítulo (Descrever, Ilustrar ou Experimentar?) questiona o espaço e as problemáticas ao levar a imagem e o som a sério no campo antropológico. Os filmes apresentam o mundo de modo relativo a determinado encontro particular, constroem o que Piault chama de "situação antropológica": põem em perspectiva e questionam a própria descrição e abordagem antropológicas, as partes implicadas nas relações constituintes e os limites de suas capturas. Antes que se perder entre a pura ficção ou a ilusão de reprodução objetiva do real, explora tal encontro, suas possibilidades e o que (nos) retorna. Retorno este que oferece não somente aspectos desses outros distantes agora próximos, como também os avatares de nosso pensamento, o avanço e o regime colonial a que estavam submetidos.

Nestes anos entreguerras, o cinema ganhava espaço frente ao grande público, enquanto os filmes etnográficos/antropológicos continuavam restritos aos especialistas. Os capítulos 7 e 8 (O Estrondo da História e CinemaVerdade - Cinema Direto) traçam a paisagem da cena cinematográfica no pós-guerra na Europa, em que a implicação política, o comprometimento, o engajamento são as palavras de ordem. As mudanças de olhar deslocam a busca pelas grandes diferenças, o exotismo é problematizado e o cinema se volta ao real próximo: às comunidades rurais, às classes trabalhadoras no próprio continente, como no Neorrealismo italiano. Tal experimentação busca construir um espaço de verdadeira interlocução, no qual "objetos" possam ser vistos e pensados enquanto "sujeitos", em sua inteireza, o real que vivem como a realidade última a se construir com (não sobre) eles.

O exemplo do "biodocumentário" de Worth e Adair (:231) entre os Navajo explora o encontro entre saberes (os cineastas ensinam aos indígenas o manuseio do equipamento e passam a um processo de discussão e coletivização das etapas de criação) e retorno (avaliação constante do material produzido e editado). Seguindo, a inserção de som sincrônico - os sujeitos falam por si mesmos - no "cinema direto" é, sem dúvida, 
fundamental para explicitar o projeto interlocutivo, a saída da objetivação para a subjetivação daqueles que se filmam e são filmados, em que acompanhar o outro, "mimetizar" seu comportamento, se faz imperativo. Aqui, as imagens são exploradas em sua polissemia, em que não se busca mais eliminar a presença e intenções do observador, e sim explorar tais recortes e modalidades do olhar de diversas regiões do mundo, como o Canadá, os EUA, a Itália e a França.

Próximo à conclusão, nos capítulos 9 e 10 (Rumo a um Etnocinema e Antropologia e Cinema. Moral e Política), as primeiras tentativas no "cinema direto" e na captura da "vida de improviso", ainda deixavam os outros no lado de lá da captura, às vistas da lente. A construção de um "etnocinema" devém do reconhecimento das posições no diálogo e das (in)compreensibilidades mútuas próprias ao encontro de interconhecimento, uma troca, na "situação etnográfica". A atenção recai sobre as transformações, as lidas diferentes das múltiplas sociedades com a diferença causada pelo avanço da colônia, como tão bem são pensadas nos filmes de Jean Rouch. As passagens do eu ao outro, abertura fugidia à alteridade num projeto sempre inacabado de engajamento e compreensão marca seu cinema e, em concomitância, a empresa antropológica.

Piault resume: "é aí que reside uma parte da empreitada, aproximar-se do que expressa cada vivência particular e refletida do mundo: apossar-se e desapossar-se de si e dos outros, o caminho do que será a antropologia partilhada de amanhã está sendo trilhado" (:332). Assim, numa descrição sempre problemática em interlocução com um outro, a antropologia consegue torcer as perspectivas, inverter os olhares e as posições de observação, escuta, fala e escrita. O filme sobre a apropriação trobiandesa do críquete inglês (Trobriand Cricket: An Ingenious Response to Colonialism, 1975) é um bom exemplo da "descolonização pela imagem": as reinvenções e reversões de "outros" sobre "nós" são boas para pensar os lugares de tais termos, as agências, contornos e reforços de tais "Grandes Divisões". O "cinema participante" e a "antropologia partilhada" - a antropologia visual - reelaboram o que deveria ser a tarefa da antropologia em geral: "O objetivo já não é, na realidade, descrever os fatos e os objetos, mas tornar pensável a possibilidade de toda relação e de sugerir coordenadas e modalidades lógicas e concretas para seu estabelecimento, sua busca e... sua transformação!” (: 244). 
Piault foi um grande antropólogo-cineasta que sistematizou e defendeu o lugar da antropologia audiovisual, não somente como um campo, sim como um espaço de interlocução e criação que põe toda a antropologia, "como método", em questão, como diz em sua Conclusão. A relação entre "eu" e "outro", as implicações políticas das relações construídas na interação, a importância dos pontos de vista de quem fala. Antes que afirmação de autoridade de antemão inegociável, abre a oportunidade para a real imbricação de um projeto compartilhado, por meio de um alargamento de nosso campo focal fazendo uma panorâmica da produção e reflexão audiovisual da disciplina. Tendo em vista a construção desses espaços de interlocução, reversão e relação entre perspectivas, a antropologia nunca deixa de se interrogar acerca de suas práticas e intenções, atentando aos olhares e às escutas presentes e complexas de outrem.

Um exemplo de tal potencialidade está no filme Xapiri (2012), realizado por Bruce Albert, Gisela Motta, Laymert Garcia Dos Santos, Leandro Lima, Stella Senra entre os Yanomami, da aldeia Watoriki, no Amazonas, que diz não sobre o xamanismo enquanto explicação homogeneizante e pedagógica, e sim busca acompanhar as viagens, os trânsitos, passeios, trocas e visões de tais rituais intelectivos entre homens e espíritos. A miscelânia de visualidades, cores, efeitos, trucagens na montagem reconstrói e emula, para nós espectadores, o tom e o percurso próprio da comunicação espiritual dentro da "floresta de cristal" na cosmologia yanomami. O cinema e a antropologia têm muito a ganhar com tal encontro que Piault fornece as pistas e os rastros de uma história e as possibilidades de imaginação de um futuro.

\section{REFERÊNGIAS BIBLIOGRÁFICAS}

CLIFFORD, James \& MARCUS, George E. (org.). 1986. Writing Culture: the poetics and politics of ethnography. Univ of California Press.

WAGNER, Roy. 2018. A invenção da cultura. São Paulo: Ubu Editora.

\section{FILMOGRAFIA GITADA}

HOMEM com uma câmera, (O). Dziga Vertov. URSS. 68 min, 1929. 
8 | HÉRCULES GOMES DE LIMA

NANOOK, o Esquimó. Robert Flaherty. Revillon Frères. 70 $\min , 1922$.

TROBRIAND Cricket: An Ingenious Response to Colonialism. Gary Kildea \& Jerry Leach. UK/USA. 50 min, 1975.

XAPIRI. Leandro Lima, Gisela Motta, Laymert Garcia dos Santos, Stella Senra, Bruce Albert. Brasil. 55 min, 2012.

Enviado: 26 de janeiro de 2021 Aceito: 3 de fevereiro de 2021 